PAA A $=95-13$
RAA-Ro-75-150 no.

\title{
PERFORMANCE EVALUATION OF DATA MODEMS FOR THE AERONAUTICAL SATELLITE CHANNEL
}

\author{
C.B. Duncombe
}

H. Salwen

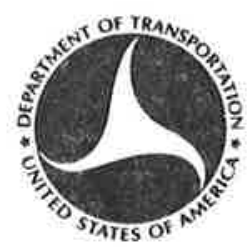

SEPTEMBER 1975

INTERIM REPORT

DOCUMENT IS AVAILABLE TO THE PUBLIC THROUGH THE NATIONAL TECHNICAL INFORMATION SERVICE, SPRINGFIELD, VIRGINIA 22161

\author{
Prepared for \\ $U, S$, DEPARTMENT OF TRANSPORTATION \\ FEDERAL AVIATION ADMINISTRATION \\ Systems Research and Development Service \\ Washington DC 20591
}




\section{NOTICE}

This document is disseminated under the sponsorship of the Department of Transportation in the interest of information exchange. The United States Government assumes no liability for its contents or use thereof. 
TECHNICAL REPORT STANDARD TITLE PAC,

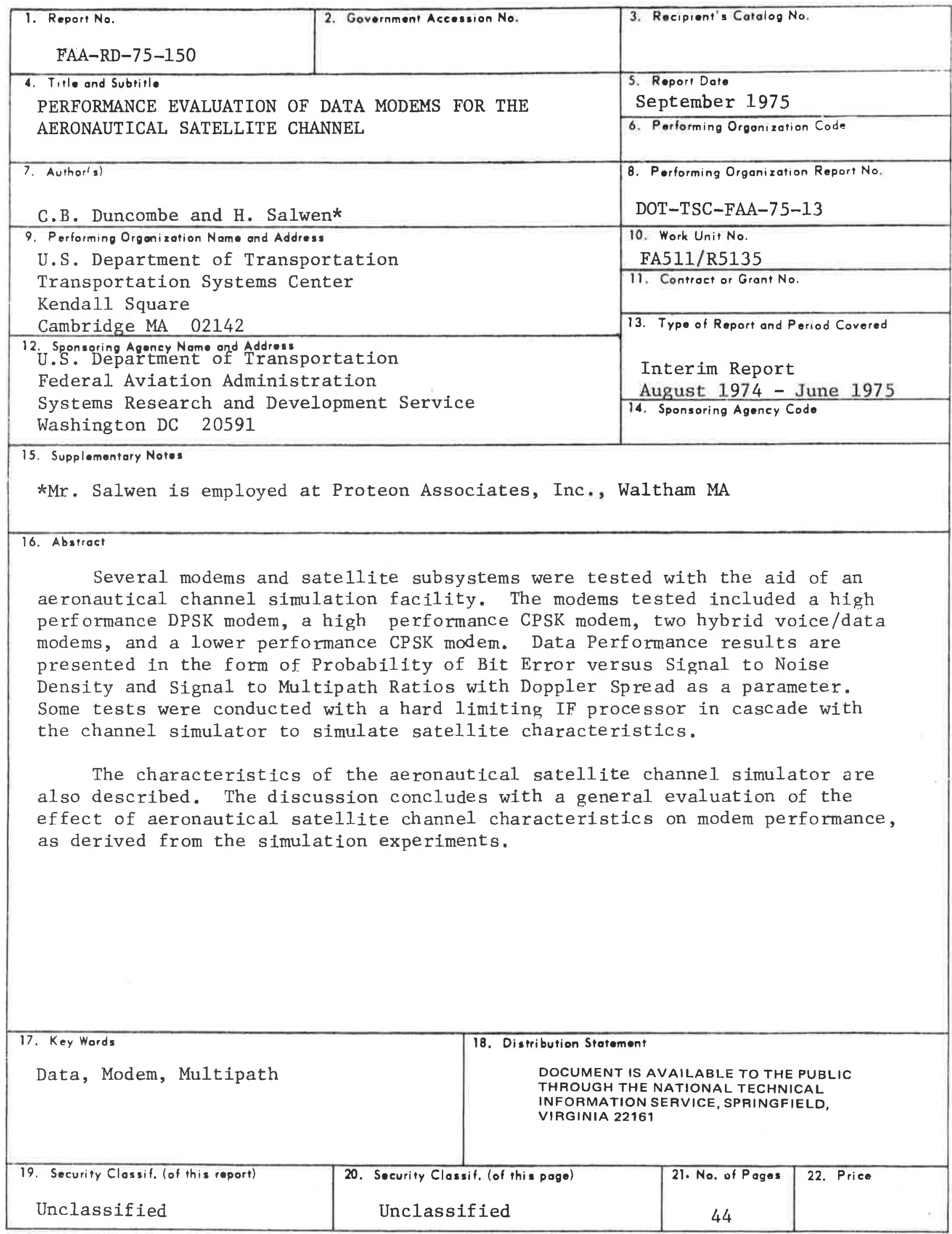

Form DOT F $1700.7(8-69)$ 

Results obtained at the U.S. Department of Transportation's Transportation Systems Center of data modem performance when tested in conjunction with TSC's aeronautical channel simulator are presented. TSC has established an aeronautical satellite-toaircraft channel simulation facility for the purpose of evaluating candidate modems to be used in the L-band satellite-to-aircraft channel. The simulator also simulates the maritime satelite-toship propagation channel. The main purpose of the facility is to test candidate modems in the laboratory and thus avoid the costly and time-consuming process of field experimentation.

The authors wish to thank Joseph Gutwein, Project Management Office, and Peter D. Engels, Chief Avionics Branch, for their assistance in assembling this report. 



\section{CONTENTS}

Section $\quad \underline{\text { Page }}$

1. INTRODUCTION $\ldots \ldots \ldots \ldots \ldots \ldots \ldots \ldots \ldots \ldots \ldots \ldots \ldots \ldots \ldots \ldots \ldots$

2. CHANNEL CHARACTERIZATION AND SIMULATOR DESIGN....... 3

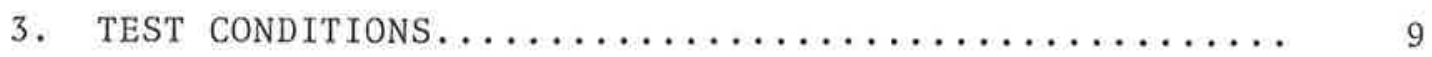

4. TEST CONFIGURATION...................... 12

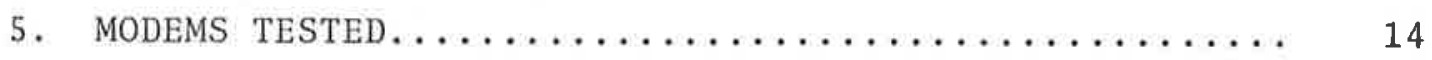

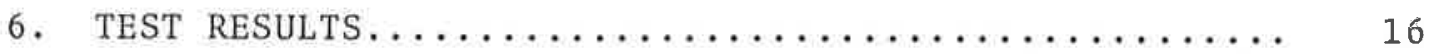

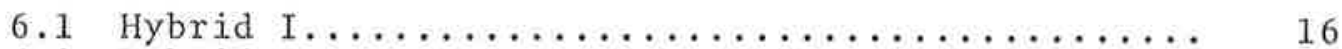

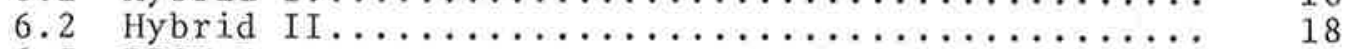

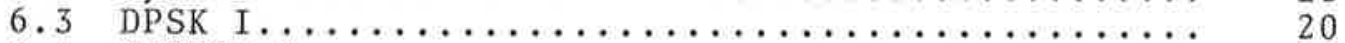

6.4 DECPSK I. . . .

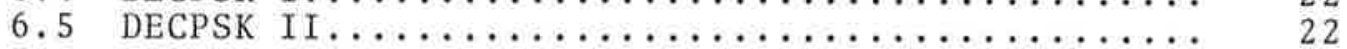

6.6 Effects of A Hard Limiting Satellite Transponder 22

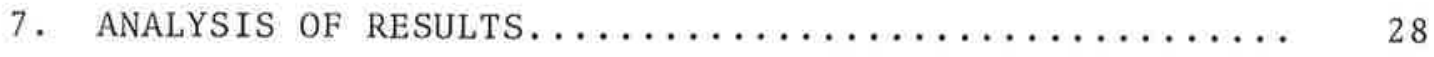

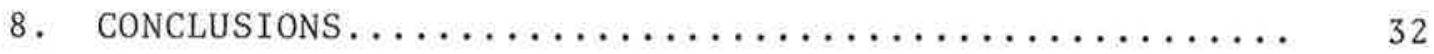

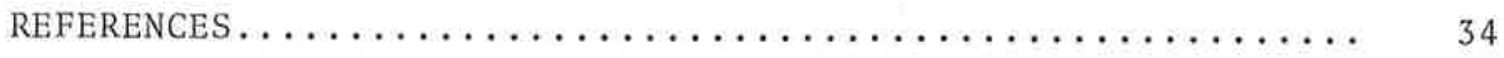




\section{LIST OF ILLUSTRATIONS}

Figure Page

1. Aeronautical-Satelite Channel Simulator.......... 8

2. Test Configuration .................... 13

3. Hybrid I Performance................. 17

4. Hybrid II Performance................... 19

5. DPSK I Performance..................... 21

6. DECPSK I Performance.................... 23

7. DECPSK II Performance...................... 24

8. Hybrid I Performance with IF Processor........... 25

9. Doppler Offset Effects.................. 26 


\section{LIST OF TABLES}

Table $\quad \underline{\text { Page }}$

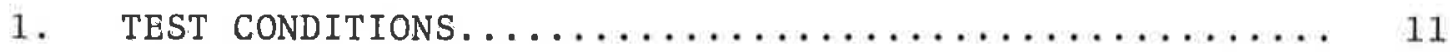

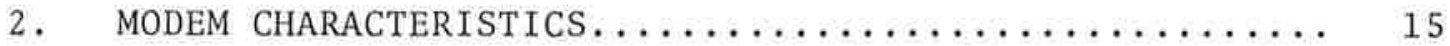

3. COMPARISON OF PERFORMANCE - HYBRID I VS. DPSK I

(TABLE ENTRIES ARE INCREASES IN HYBRID I $\mathrm{C} / \mathrm{N}_{O}$ TO ACHIEVE PERFORMANCE OF DPSK I UNDER THE SAME

CONDIT IONS) 



\section{INTRODUCTION}

The design of aircraft avionics for use in aeronautical-satellite systems must include consideration of the effects of aircraft-satellite propagation characteristics. In the aeronauticalsatellite case, the signal-to-additive noise ratio is marginally above that required by system performance criteria. Thus, the added degradation resulting from the presence of multipath components reflected from the earth's surface must be minimized. This can be achieved through the application of careful antenna design, modem design, coding techniques, or a combination of these approaches. A design tradeoff among these approaches is necessary to produce an airborne terminal optimized with respect to cost and performance.

This paper summarizes the work carried out at the U.S. Department of Transportation to characterize the performance of a variety of existing data modem equipment in the presence of simulated multipath and noise. The results obtained through the simulation experiments can be used in a tradeoff analysis leading to an optimum airborne terminal configuration.

The theoretical evaluations of performance of modems in the multipath environment provide some insight into the degradation mechanisms. 1,2,3,4 However, such analyses typically ignore part of the modem functions, such as bit synchronization or carrier extraction and their interaction with the multipath distorted signal. Alternatively, some analyses incorporate these secondlevel processes, but the number of approximations and assumptions necessarily employed limit the usefulness of the results.

The analytic complexity of a complete modem performance evaluation in the presence of multipath and the very high cost associated with flight testing of aeronautical-satellite avionics equipment lead to the desireability of a channel simulation facility for modem evaluation.

In addition to substantial cost savings, the simulator approach offers several other advantages relative to flight test 
evaluation procedures. For example, the simulator can be implemented in a manner which allows for exactly repeatable channel fluctuations. Thus it is possible to compare the performance of different modem techniques under identical channel conditions. Furthermore, the simulator facility can be used as a tool to aid in the development of new modem techniques and subsystems which are optimized for operation on aeronautical satellite links. In this mode of operation, the simulator is used to obtain the performance of an experimental modem as a function of various modem parameters such as 100 p bandwidths, integration times, filter shapes, etc., under precisely repeatable conditions. 


\section{CHANNEL CHARACTERIZATION AND SIMULATOR DESIGN}

A simulator system was designed to fulfill the modem evaluation and development objectives described above. ${ }^{5}$ The 1 aboratory system simulates multipath corresponding to a wide range of actual conditions to be encountered on aircraft-satellite links.

The aircraft-satellite channel has two major propagation paths, the direct path between the aircraft and satellite, and a multipath component between the aircraft, the earth's surface, and the satellite. The satellite is assumed to be geosynchronous, although other orbits can be accommodated. The direct path is characterized by transmission loss (free space), time delay, scintillation and atmospheric fading, and Doppler shift. The transmission loss is simulated by adding noise at the system output so that an appropriate direct-path signal power-to-noise density ratio is established at the input to the demodulation equipment under test. The absolute time delay of the direct-path signal is, of course, ignored in the simulator design. Scintillation and atmospheric fading of the direct path component is not simulated by the system. This effect was not included because the system is intended to simulate channels in which multipath fading is the predominant effect. The received signal Doppler shift is simulated over a range of $\pm 1000 \mathrm{~Hz}$ (nominal). This range accommodates radial ve1ocity components between aircraft and satellite on the order of 400 knots at $1.6 \mathrm{GHz}$.

The multipath component is characterized by its relative multipath power, relative multipath delay, relative multipath Doppler shift and Delay-Doppler scatter function. The relative multipath power is the average power in the total multipath component relative to the average direct path power. The simulator provides capability for the establishment of any ratio between direct and multipath power from all-direct (no multipath) to all multipath. Typical values for the aeronautical satellite link direct-tomultipath ratios vary in the range from $0 \mathrm{~dB}$ to $20 \mathrm{~dB}$, depending 
on the simulated system's antenna configuration and the characteristics of the terrain traversed.

The relative multipath delay is the delay of the specular point multipath component relative to the direct path component. This delay approaches zero when the satellite is on the horizon relative to the aircraft. It is maximum when the aircraft is at the subsatellite point. In that case, with the aircraft at, say, 70,000 ft the relative delay is rough1y $140 \mu \mathrm{sec}$. Most cases of interest occur when the satellite is at low elevation angle with respect to the aircraft. Thus the simulator is designed to provide 3 discrete relative multipath delays, $5 \mu \mathrm{sec}, 30 \mu \mathrm{sec}$, and $55 \mathrm{\mu sec}$. In fact, the relative multipath delay varies with vertical motions of the aircraft. This effect is merged with the delay-Doppler scatter function, as will be discussed below.

The relative multipath delay, $\tau_{m s}$, is approximated by assuming a flat earth and the satellite at infinity. Then,

$$
\tau_{\mathrm{ms}} \cong \frac{2 h}{\mathrm{c}} \sin \gamma
$$

where

$$
\begin{aligned}
& \mathrm{h}=\text { aircraft altitude } \\
& \mathrm{c}=\text { speed of light } \\
& \gamma=\text { multipath reflection grazing angle }
\end{aligned}
$$

The relative multipath doppler shift is a measure of the variation of relative delay. Assuming a flat earth and the satellite at infinity this component would be entirely due to vertical aircraft motions. For most cases, the relative doppler, $f_{m s}$, is well approximated by

$$
\left.f_{m s} \cong-v_{h} \frac{\left(f_{c}\right.}{c}\right) \sin \gamma
$$

where

$$
v_{h}=\text { aircraft vertical velocity }
$$




$$
f_{c}=\text { carrier frequency }
$$

The simulator provides a relative doppler range of $\pm 100 \mathrm{~Hz}$. This corresponds to a $180 \mathrm{ft} / \mathrm{sec}$ vertical velocity component at $1.6 \mathrm{GHz}$ at a grazing angle of $10^{\circ}$ or a $60 \mathrm{ft} / \mathrm{sec}$ vertical velocity component at $1.6 \mathrm{GHz}$ at a grazing angle of $30^{\circ}$.

The delay-Doppler scatter function for multipath on aircraftsatellite links has been the subject of intensive investigation (see References 6, 7, and 8 for examples) and thus will not be discussed in depth here. The overall delay spread, i.e. the integral of the delay-doppler scatter function over doppler, at the $-10 \mathrm{~dB}$ contour is approximately (Reference 7, eq. (15)):

$$
\tau_{\mathrm{ds}} \cong \frac{2 \mathrm{~h}}{\mathrm{c}} \beta_{\mathrm{o}}^{2}
$$

where $\beta_{0} / \sqrt{2}$ is the r.m.s. surface-slope $(\sqrt{2} \sigma / L)$. The delay power spectrum shape for various elevation angles is shown in Reference 8, Figure 5. Thus, assuming an aircraft at 50,000 ft and $\beta_{0} \cong 0.2828$, the delay power spectrum will extend over several microseconds.

The overall doppler spread, i.e. the integral of the delaydoppler scatter function over all delays, is given by ${ }^{8}$

$$
D \cong\left(\frac{2 f_{o}}{c}\right)(2 \alpha) v \sin \gamma
$$

assuming that vertical velocity components are negligible. An upper bound on r.m.s. Doppler spread can be obtained by assuming a Mach 3 aircraft $(v=3000 \mathrm{ft} / \mathrm{sec})$ and $\alpha=0.2$ (i.e. $\beta_{0}=0.2828$ ). In that case D at $1.6 \mathrm{GHz}$ is approximately $3840 \mathrm{sin} \gamma \mathrm{Hz}$ or, for example, $1920 \mathrm{~Hz}$ when $\gamma=30^{\circ}$. The doppler spectrum for multipath components which are delayed relative to the specular multipath component have been shown to be bimoda ${ }^{6,9}$ with most of the spectral energy piled up at the edges of the bandwidth and the bandwidth increasing with increasing delay.

The simulator implements the channel's delay doppler scatter function by means of a tapped delay line. Specifically, 5 taps 
2 usec apart are employed. Thus valid channel models can be created for signal bandwidths on the order of 200-300 kHz or 1 ess. At each tap, the delayed signal component is split into in-phase and quadrature components. These are modulated in balanced modulators by independent low-pass gaussian noise functions to create a Rayleigh fading process. The bandwidth of the noise at each tap is independently controllable and can be set to create the desired doppler-as-a-function-of-delay characteristic. However, the simulator cannot create any desired spectral shape at each tap. Instead, the low-pass gaussian processes have second-order Butterworth shapes. Specifically, the filter shape is by definition,

$$
H(s)=\frac{2 a^{2}}{s^{2}+2 a s+2 a^{2}} ; \quad|H(\omega)|^{2}=\frac{1}{1+\left(\omega^{4} / 4 a^{4}\right)}
$$

The $3 \mathrm{~dB}$ bandwidth of this filter is

$$
f_{3 \mathrm{~dB}}=\frac{\sqrt{2}}{2 \pi} \mathrm{a}
$$

The second moment (mean-square bandwidth) of the filter is by definition

$$
\beta^{2}=\frac{\int_{-\infty}^{\infty} \omega^{2}|\mathrm{H}(\omega)|^{2} \mathrm{~d} \omega}{\int_{-\infty}^{\infty}|\mathrm{H}(\omega)|^{2} \mathrm{~d} \omega}=2 \mathrm{a}^{2}(\mathrm{rad} / \mathrm{sec})^{2}
$$

Finally, the Doppler spread, D, of the process is defined (Reference 8, p. 559) as twice the standard deviation (r.m.s. bandwidth). That is,

$$
\mathrm{D}=\frac{2 \sqrt{2} \mathrm{a}}{2 \pi}=2 \mathrm{f}_{3} \mathrm{~dB}(\operatorname{Hertz})
$$

Front-panel controls are provided on the simulator to set the bandwidth of each of the five tap modulation processes. These controls are calibrated directly in r.m.s. Doppler spread (Hertz). Doppler spreads in the range from $10 \mathrm{~Hz}$ to $1.999 \mathrm{kHz}$ can be generated. Each of the ten independent low-pass gavsian processes 
is generated from $2^{39}-1$ pseudo-random sequences. The sequences can be reinitialized at any time by depressing a reset control. Thus the fading effects created by the simulator are exactly repeatable. In addition, the sequence generators can be stopped and restarted by a front-pane1 control. In this way, the simulator can provide a "frozen-channel" for experiment purposes. In operation, the instantaneous delay through the tapped delay line portion varies dynamically. This effect overshadows the slow changes in relative multipath delay which are not simulated. Figure 1 shows a block diagram of the aeronautical-satellite channel simulator. Note that the simulator input and/or output can be at a $70 \mathrm{MHz}$ I.F. or at L-Band. The system also provides test and monitoring functions. 


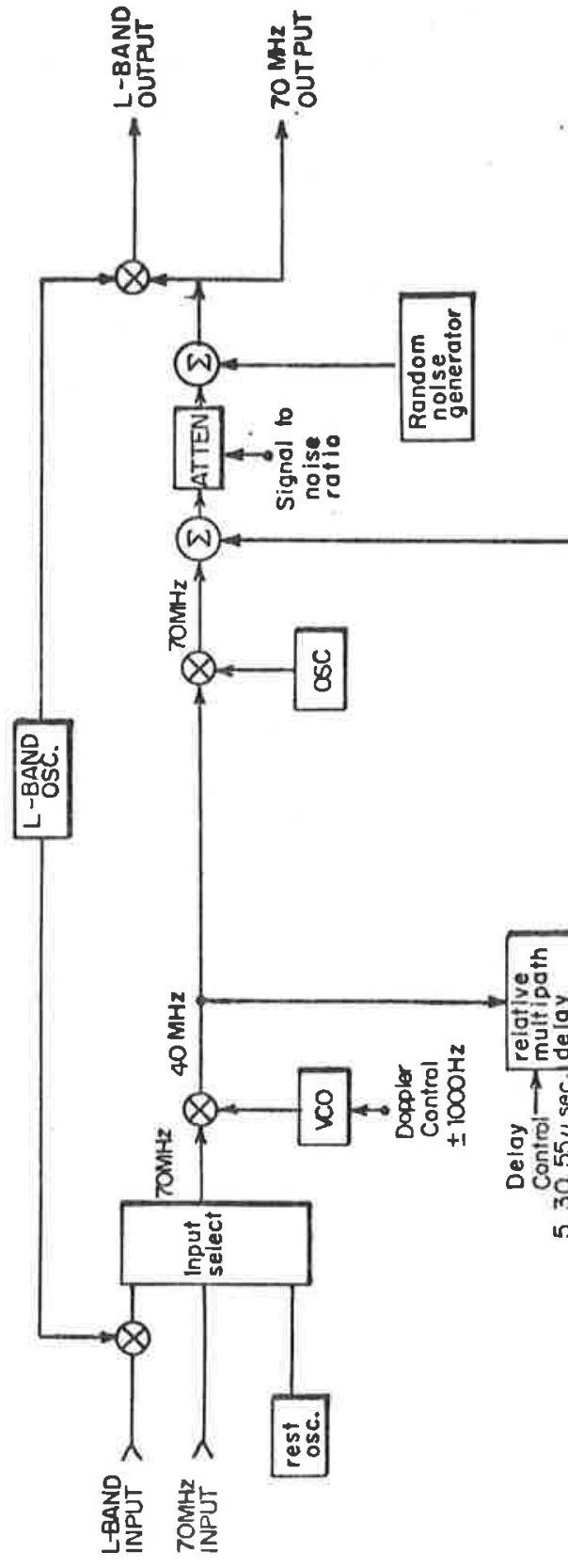

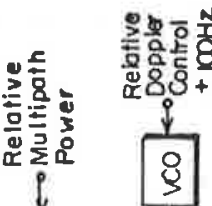

蛋

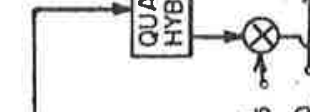

品空
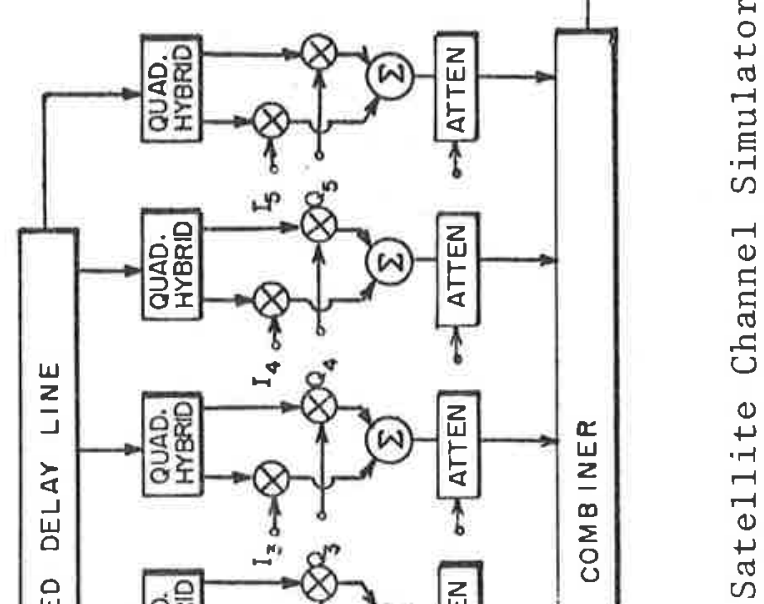

(4)
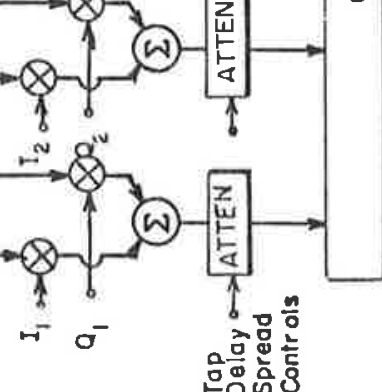

D 


\section{TEST CONDITIONS}

Most of the data modem tests described in this report are measurements of bit error rate (BER) versus direct path carrierto-noise density $\left(\mathrm{C} / \mathrm{N}_{\mathrm{O}}\right)$ as a function of two multipath parameters, namely, the carrier-to-multipath ratio $(C / M)$ and the multipath doppler spread, D. Three values of $\mathrm{C} / \mathrm{M}$ were chosen for test purposes, $5 \mathrm{~dB}, 8 \mathrm{~dB}$, and $11 \mathrm{~dB}$. The relative power of the reflected multipath signal is a function of the multipath reflection angle and the characteristics of the reflecting surface. The range of this parameter over sea water is from $-2 \mathrm{~dB}$ to $-5 \mathrm{~dB}$.* The multipath actually seen by the communication system is reduced by antenna discrimination. However, the multipath attenuation achieved by this means under low reflection angle conditions will not be significant. Therefore, the smallest $\mathrm{C} / \mathrm{M}$ ratio used in the tests was selected to be $5 \mathrm{~dB}$. This corresponds to the case in which relative multipath power is $-5 \mathrm{~dB}$ with no antenna discrimination between direct and multipath components or, for example, where relative multipath is $2 \mathrm{~dB}$ down and the antenna provides $3 \mathrm{~dB}$ of discrimination against the multipath. Based on channel modelling for aircraft-to-satellite links carried out to date it appears that $\mathrm{C} / \mathrm{M}=8 \mathrm{~dB}$ is typical of such links over water using hemisherical coverage (turnstile) antennas at low elevation angles. 9 Finally, the $11 \mathrm{~dB}$ ratio corresponds to the case in which a more sophisticated antenna, such as a 3 -element switched antenna system, is used. 10

The r.m.s. multipath spreads used in most of the test runs were $10 \mathrm{~Hz}, 100 \mathrm{~Hz}, 1 \mathrm{kHz}$ and $2 \mathrm{kHz}$. A $10 \mathrm{~Hz}$ Doppler spread is a 1 ower bound on this parameter when the multipath reflection occurs on the sea-surface. In that case $10 \mathrm{~Hz}$ of Doppler spread is attributable to sea-surface motion. A $100 \mathrm{~Hz}$ Doppler spread is typical of that

*This discussion emphasizes sea-surface reflections rather than terrain reflections since they are larger and therefore more troublesome. The results can be applied to terrain reflections given an estimate of the relative multipath power. 
expected on satellite-to-subsonic aircraft 1inks. ${ }^{11}$ Finally, the $1 \mathrm{kHz}$ and $2 \mathrm{kHz}$ spreads may be experienced by SST type aircraft.

As discussed above, the simulator can apply relative doppler shifts and various relative multipath delays. These were found to have little or no effect on the performance of the specific modems tested. Specifically, tests were conducted with relative multipath delay. set at $5 \mathrm{\mu sec}$ and $55 \mathrm{\mu sec}$. A $5 \mathrm{\mu sec}$ delay is experienced, for example, by an aircraft at $20,000 \mathrm{ft}$ when the multipath reflection angle (elevation to the satellite) is approximately 7 degrees. The 55 usec delay occurs when, for example, an aircraft at $40,000 \mathrm{ft}$ is positioned so that the elevation angle to the satellite is approximately 43 degrees. The modem performances observed at these two relative multipath delay settings were not significantly different. Therefore, all the results presented below are for the case in which relative multipath delay is 5 usec. In a few cases, performance degradation as a function of relative Doppler shift was measured. The results of these tests will be presented below.

Note that the simulator can create multipath delay spreads of up to $10 \mu \mathrm{sec}$ in delay by energizing up to 5 of the tap multiplier units shown in Figure 1. Such exact multipath simulation is required when the bandwidth of the transmitted modem signal is on the order of $\frac{1}{\text { multipath delay spread. The bandwidths of the modem }}$ outputs at $1200 \mathrm{bit} / \mathrm{sec}$ or $2400 \mathrm{bit} / \mathrm{sec}$ are much smaller than the anticipated multipath spread. Thus, the effect of simulating the multipath spread using 5 taps should be negligable relative to the effect acheived with a single tap model. This hypothesis was tested and found to be correct. Therefore, all modem tests reported here were carried out using a single tap channel model. A summary of test conditions is shown in Table 1. 


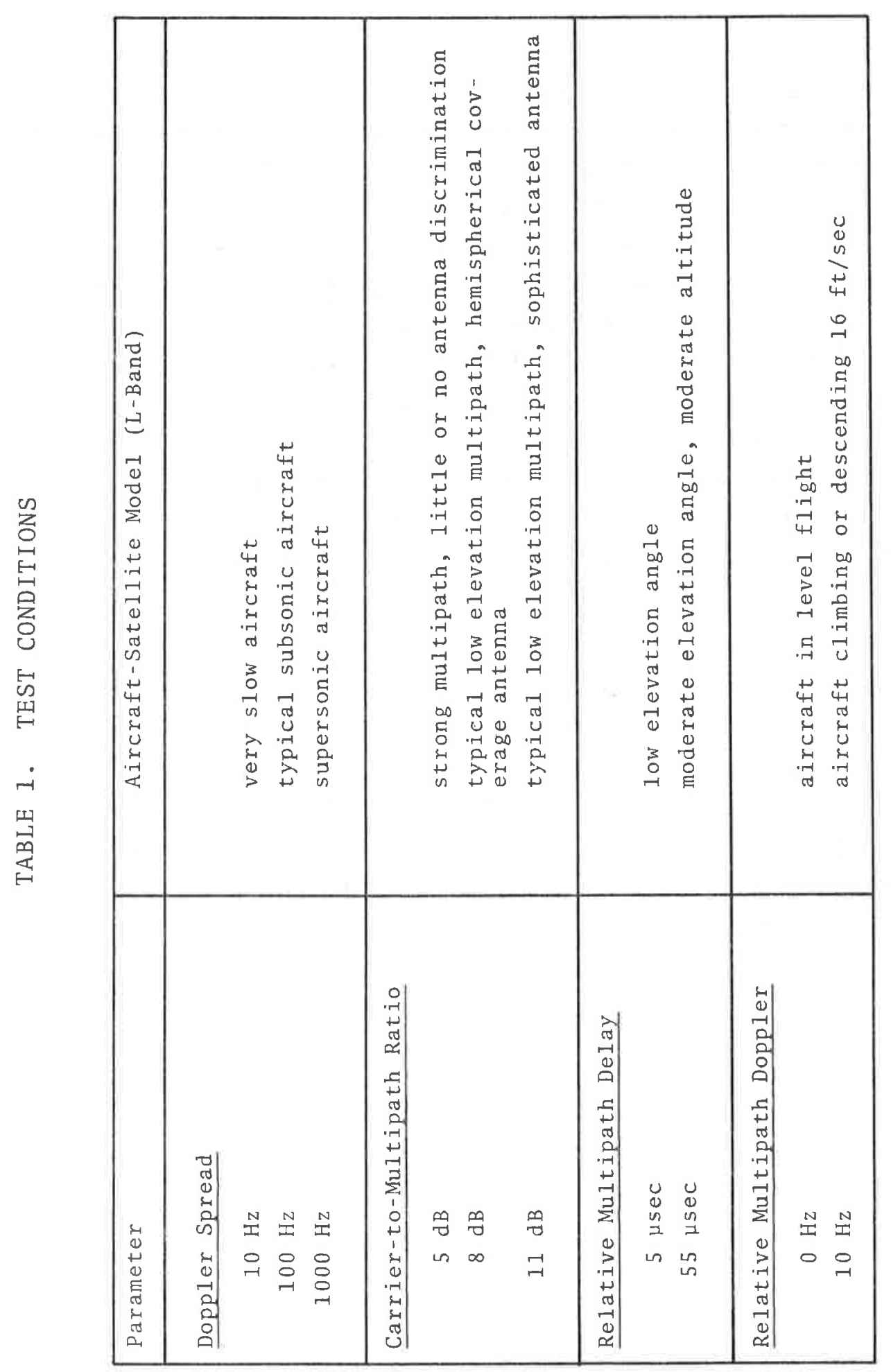




\section{TEST CONFIGURATION}

A block diagram of the test set up is shown in Figure 2. The modulator portion of the modem under test is driven by a test signal generator. In all cases the test signal used is a 2047 bit maximum-length shift register sequence. The $70 \mathrm{MHz}$ output of the modulator is passed through the simulator where multipath distortion effects are produced and a controlled amount of bandpass gaussian noise is added to the process. The simulator output is either applied directly to the demodulator portion of the modem, or is converted to another IF before application to the demodulator if required. The data output of the demodulator under test is analyzed by a bit-error-rate test set which counts the transmission errors. Signal and noise power were monitored by a precision power meter. The noise power was measured with a calibrated bandpass

filter in cascade so that noise power density, $N_{0}$, could be derived directly.

One modem was also tested in a simulated satellite transmission environment by adding a hard-1imiting IF processor in cascade with the simulator. In this case, two independent noise sources are required. One simulates noise on the uplink from aircraft-to-satellite and the second simulates noise on the downlink from satellite-to-ground station. The components for this test configuration are also shown in Figure 2 . 


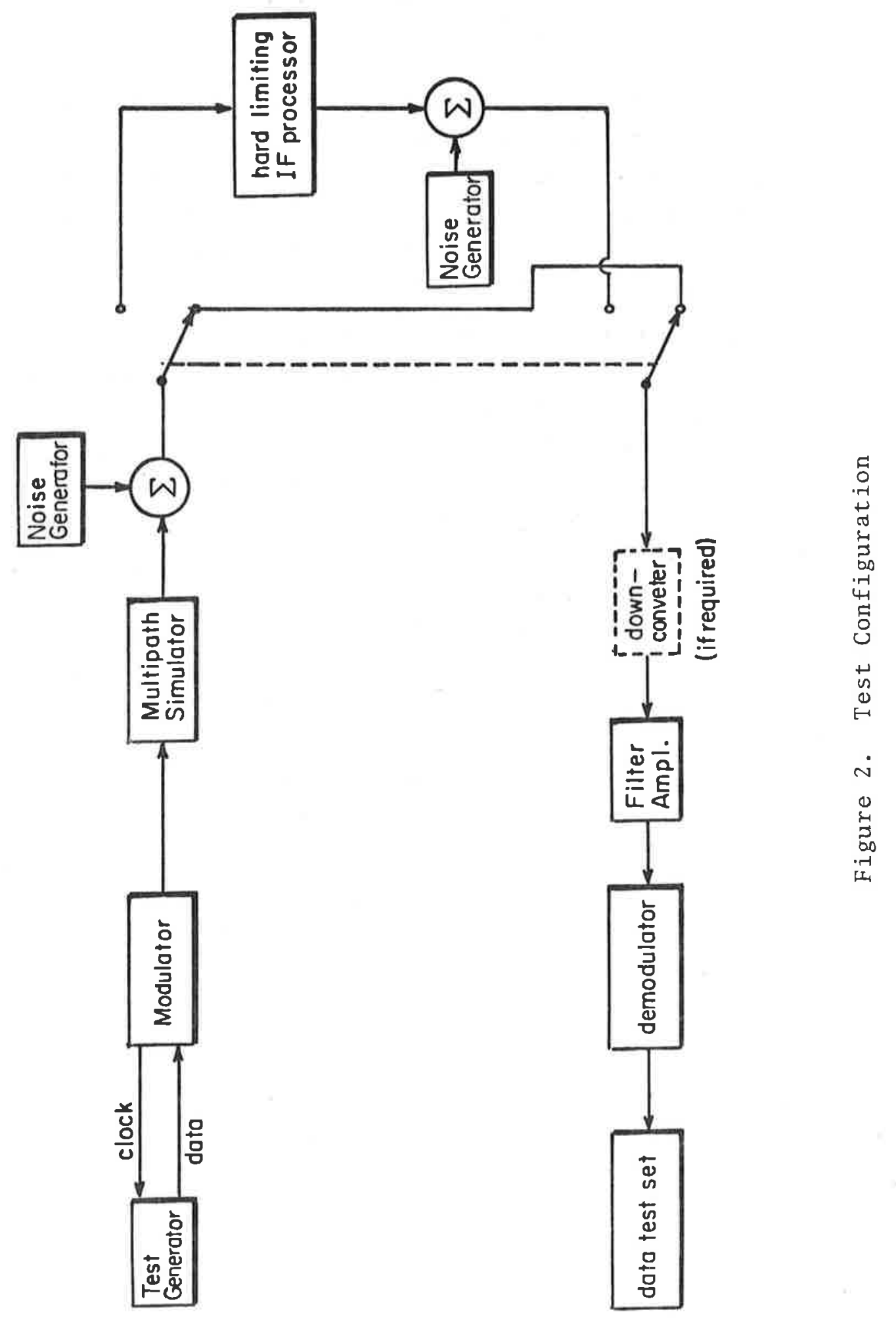




\section{MODEMS TESTED}

Five modem systems were tested using the channel simulator. In particular, two hybrid modems were tested which have the capability of simultaneous voice and data transmission on a single, constant envelope carrier. Two differentially encoded coherent phase shift deyed (DECPSK) modems and a differentially coherent phase shift keyed (DPSK) modem were also tested.

A11 modems tested operate at 1200 and 2400 bits/sec. While both hybrid modems employed quadrature modulation techniques to provide simultaneous voice/data capability, their voice modulation techniques were different. Specifically, one hybrid modem employed a type of phase modulation technique with limited maximum phase deviation for voice transmission. The second hybrid used pulse duration modulation (PDM) for voice transmission. Both hybrid modems employed DECPSK for data transmission. That is, their data detection circuitry included coherent (synchronous) demodulators. The hybrid modems and one of the DECPSK modems were designed specifically for the aircraft-satellite link. The DPSK modem and one of the DECPSK modems are rather sophisticated implementations, not specifically designed for aircraft-to-satellite links, but considered to be representative of these classes of modems.

The characteristics of these modems are summarized in Table 2. 


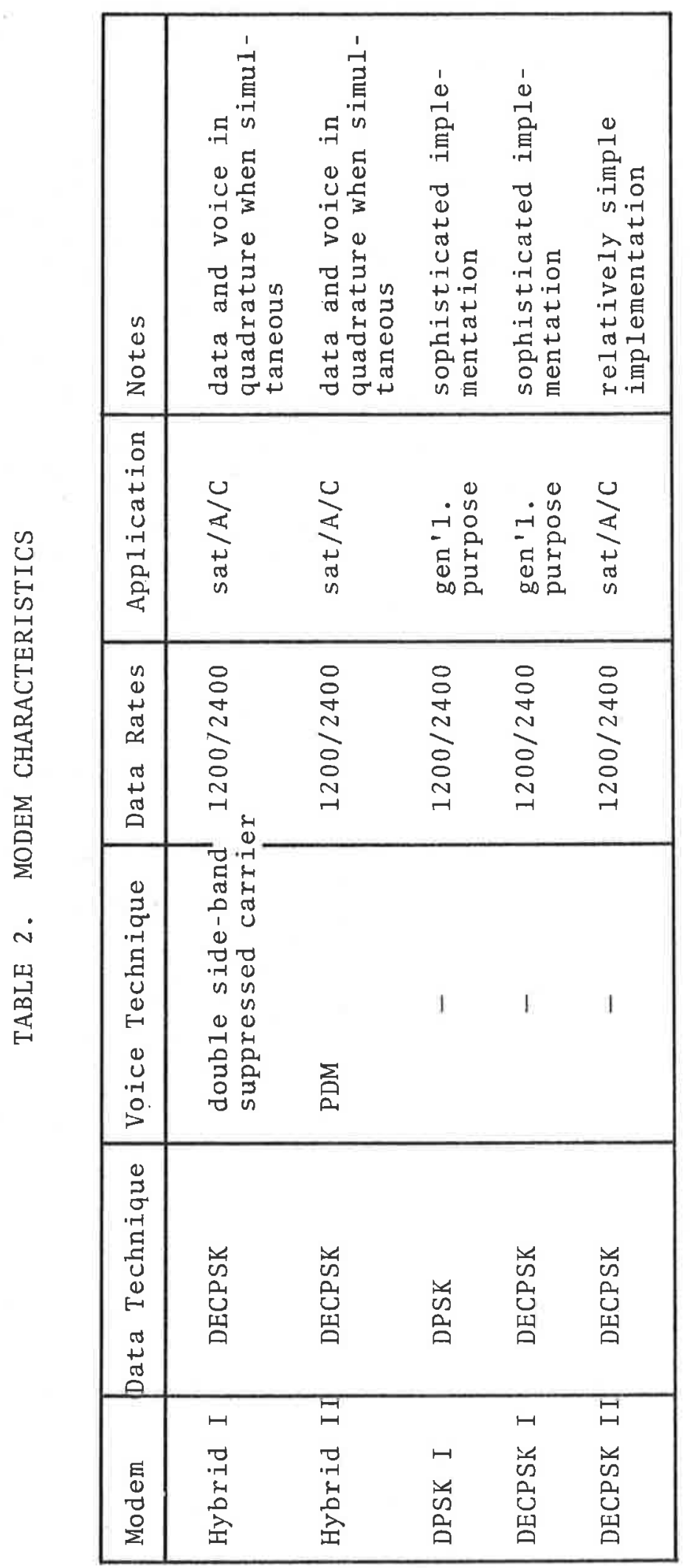




\section{TEST RESULTS}

The performance of each of the modems was tested under a variety of conditions as described above. This section presents the results of the tests and a brief analysis of the results.

\subsection{HYBRID I}

In order to get a baseline measure of performance for this modem, BER data were derived with the modulator and demodulator operating back-to-back with gaussian noise added and no multipath. The results of this test at $1200 \mathrm{bit} / \mathrm{sec}$ are shown in Figure 3 . The modem provides performance that is within $0.5 \mathrm{~dB}$ of theoretical at $1200 \mathrm{bit} / \mathrm{sec}$. A similar test at $2400 \mathrm{bit} / \mathrm{sec}$ showed that performance at this rate is within $0.6 \mathrm{~dB}$ of theoretica 1 . It is important to note, at this point, that since measurement errors on the order of $\pm 0.25 \mathrm{~dB}$ are expected for the test setup, the difference in performance observed at the two bit rates is not considered to be significant.

Next, the multipath was added with a delay of $5 \mu \mathrm{sec}$ and Doppler spreads of $10 \mathrm{~Hz}, 100 \mathrm{~Hz}, 1 \mathrm{kHz}$ and $2 \mathrm{kHz}$. BER measurements were performed as a function of $\mathrm{C} / \mathrm{N}_{\mathrm{O}}$ and for the three $\mathrm{C} / \mathrm{M}$ ratios previously discussed. The results are also shown in Figure $3 . *$

Note first that multipath significantly degrades modem performance even when it is assumed that antenna discrimination increases the carrier-to-multipath ratio to $11 \mathrm{~dB}$. For example, a typical performance criterion assumed for an aeronautical satellite link is $\mathrm{P}_{\mathrm{e}}=10^{-5}$ at $\mathrm{C} / \mathrm{N}_{\mathrm{O}}=43 \mathrm{~dB}-\mathrm{Hz}$. The data of Figure 3 show that in the presence of multipath $11 \mathrm{~dB}$ down and with a typical aircraft-satellite Doppler spread on the order of $100 \mathrm{~Hz}$, this level of performance will not be achieved by this modem. Specifically,

*The left-most curve in this figure and all other BER vs. C/N plots below is the theoretical performance. 


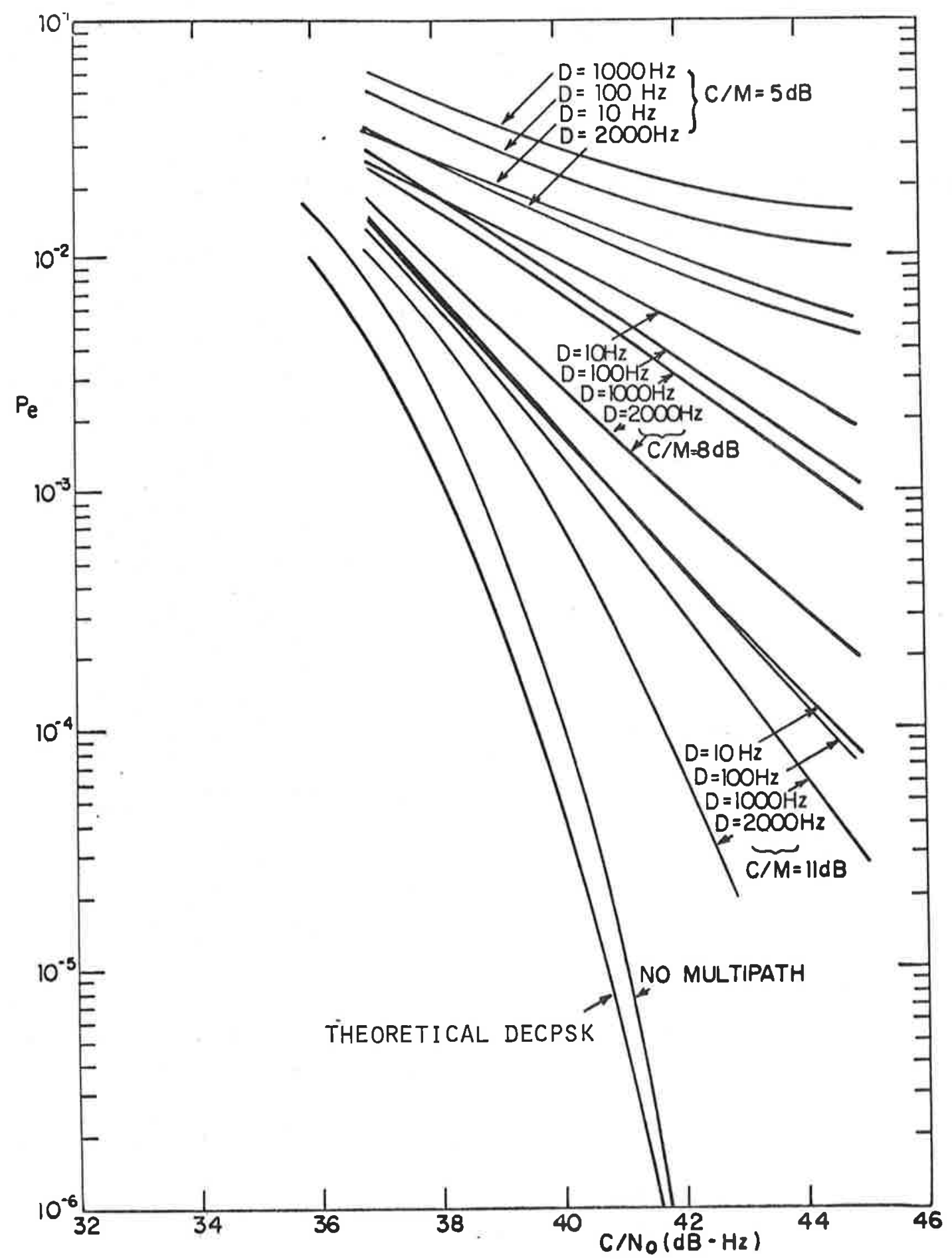

Figure 3. Hybrid I Performance 
error rates on the order of 2 or $3 \times 10^{-4}$ should be expected for this modem at $43 \mathrm{~dB}-\mathrm{Hz}$. An error of $10^{-5}$ might be achieved under these conditions when $\mathrm{C} / \mathrm{N}_{\mathrm{O}}$ is on the order of $48-50 \mathrm{~dB}-\mathrm{Hz}$. At $\mathrm{C} / \mathrm{M}$ ratios of $8 \mathrm{~dB}$ and $5 \mathrm{~dB}$ performance is significantly worse. In fact, a BER of $10^{-5}$ may be unachievable with $\mathrm{C} / \mathrm{M}=5 \mathrm{~dB}$, assuming feasible $\mathrm{C} / \mathrm{N}_{\mathrm{O}}$ ratios for aircraft-to-satellite links.

Figure 3 shows one interesting phenomenon uncovered during the modem testing operation. Namely, as Doppler spread is increased at fixed $\mathrm{C} / \mathrm{N}_{\mathrm{O}}$ and $\mathrm{C} / \mathrm{M}$ ratios, modem performance first degrades, then begins to improve again. When the Doppler spread is wide enough, performance improves beyond the slow fading case and approaches the no-multipath performance. This effect is easly explained. Specifically, as multipath bandwidth is increased with total multipath power fixed at $M$, the amount of multipath power seen in the data detection bandwidth is reduced. (The same effect also occurs in the bit-synch, and carrier loop bandwidth, but since these loops are typically narrower in bandwidth than the data detection process, the effect becomes noticeable at lower Doppler spreads.) Thus, in the limit as Doppler spread approaches infinity, the effect of multipath goes to zero. This phenomenon is discussed and analyzed in Reference 3. There, BER curves are derived on a theoretical basis for a differentially coherent modem. The results correspond qualitatively to the experimental results of Figure 3 in the sense that as Doppler spread is increased beyond the bit rate the effect of multipath is reduced.

\subsection{HYBRID II}

The data performances of Hybrid II under various conditions are shown in Figure 4. The general form of these curves is comparable to those of Hybrid I, and since the modem techniques are similar, the discussion above applies to the Hybrid II data as we 11. Note, however, that the performance achieved by Hybrid II is slightly worse than that achieved by Hybrid I in the presence of multipath, but is better than Hybrid I in gaussian noise-only. The number of actual measurements taken to produce Figures 3 and 4 rules out the possibility of random measurement error. Furthermore, since 


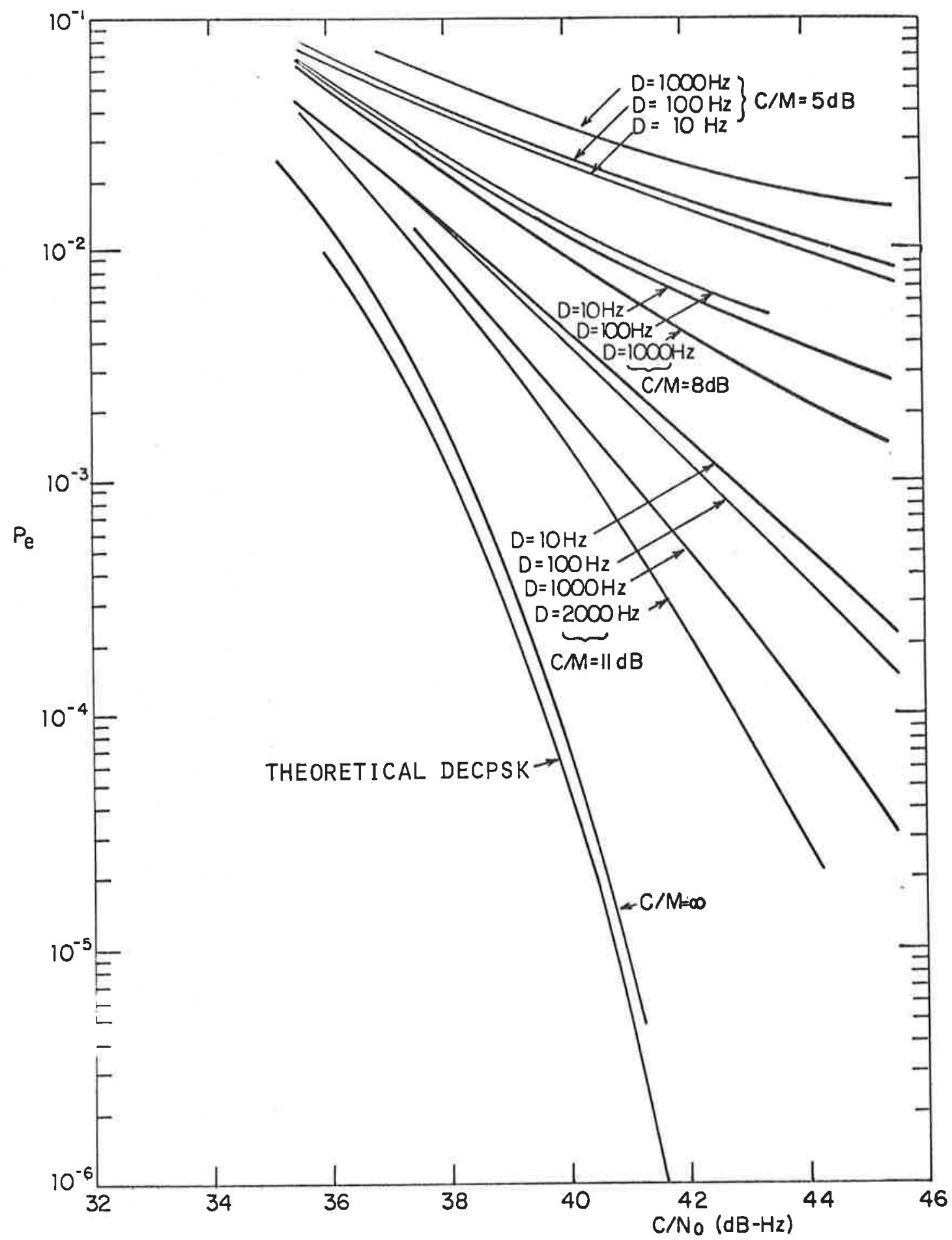

Figure 4. Hybrid II Performance 
systematic measurement errors are common to both sets of data, these sources of error cannot explain the observed difference in performance. It is possible that a small misalignment of the Hybrid II system components is responsible for the observed difference. The source of this difference in performance is considered further in the analysis discussed below.

\subsection{DPSK I}

Figure 5 shows the performance of the DPSK modem under various conditions. This DSPK modem does not use a coherent carrier reference to detect the data bits. Instead, the operation carried out by the DPSK I modem is equivalent to employing the previous transmitted bit as a reference for detecting the current bit (i.e. straightforward differentially coherent PSK). Again, performance in the presence of gausian noise only is within $0.4 \mathrm{~dB}$ of theoretical at high $\mathrm{C} / \mathrm{N}_{0}$ and within $0.8 \mathrm{~dB}$ of theoretical at low $\mathrm{C} / \mathrm{N}_{\mathrm{O}}$. Note, however, that the theoretical performance of DPSK is between $0.4 \mathrm{~dB}$ and $0.8 \mathrm{~dB}$ worse than that of DECPSK over the $\mathrm{C} / \mathrm{N}_{\mathrm{O}}$ range of interest.

The actual data collected for this modem corresponded closely to the theoretical results derived for DPSK in Reference 3 . Comparing the results of Figure 5 to those of Figures 3 and 4 , it is seen that although the DPSK modem provides inferior performance in the presence of gausian noise, it is typically better than the DECPSK modems in the presence of noise plus multipath. Moreover, the slope of the curves is substantially different. Thus, for example, the performance of DPSK $I$ at $C / M=8 \mathrm{~dB}$ is readily compared to the performance of Hybrid II with $\mathrm{C} / \mathrm{M}=11 \mathrm{~dB}$, but with a $1 \mathrm{~dB}$ reduction in $\mathrm{C} / \mathrm{N}_{0}$. A detailed comparison of DPSK I with Hybrid $I$ is carried out in the analysis section below.

The DPSK I modem was also tested at $\mathrm{C} / \mathrm{M}=5 \mathrm{~dB}, \mathrm{D}=1000 \mathrm{~Hz}$ with a relative Doppler shift of $10 \mathrm{~Hz}$. Such relative Doppler shifts would be experienced when the aircraft climbs or descends at roughly $16 \mathrm{ft} / \mathrm{sec}$ with a multipath reflection angle of 10 degrees, as noted above. The results are also shown in Figure 5. In this case, the presence of relative Doppler shift appears to have almost no additional effect on modem performance. 


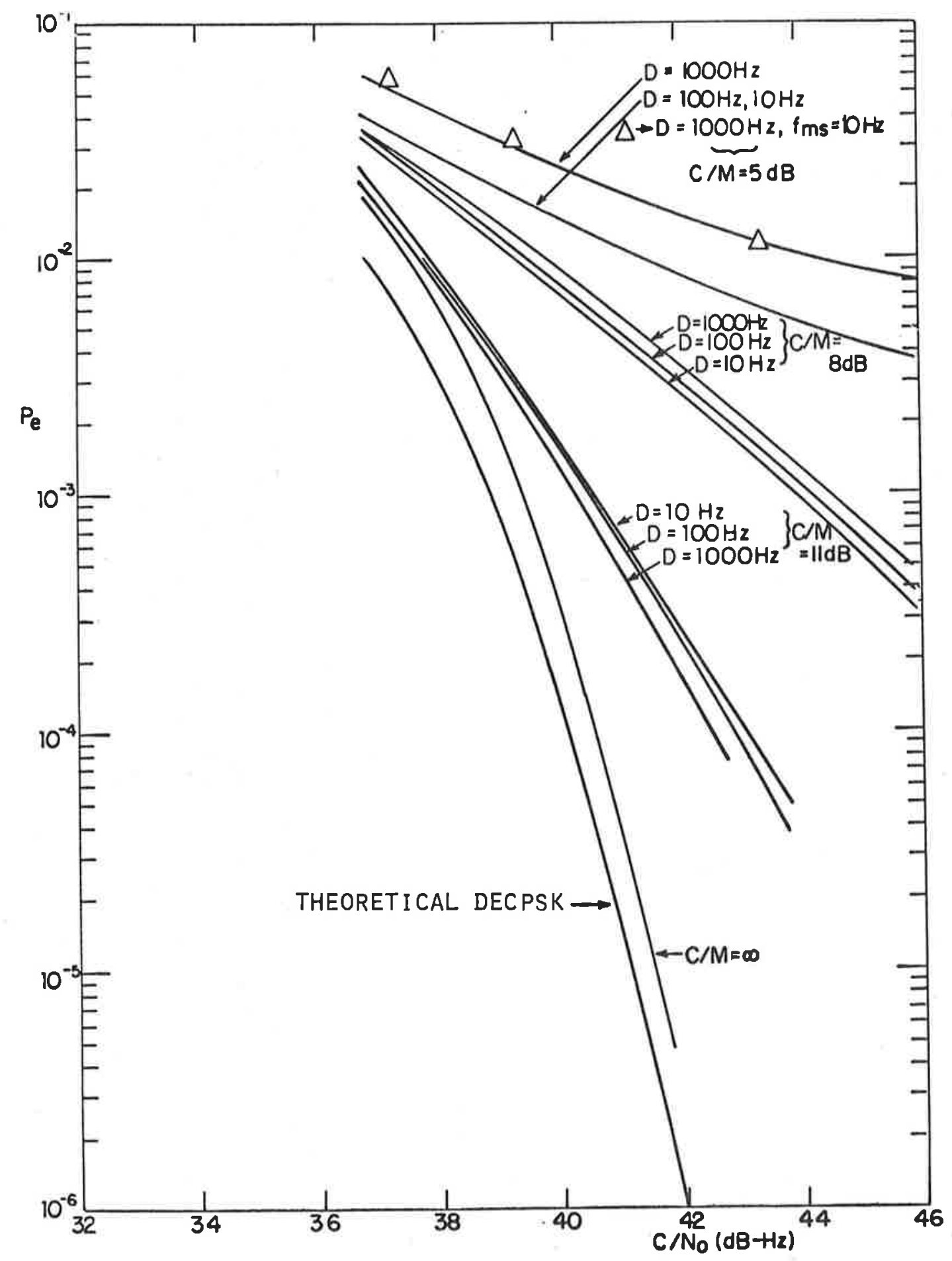

Figure 5. DPSK I Performance 


\subsection{DECPSK I}

Figure 6 shows the performance of DECPSK I. This data modem implementation produced performance somewhere between those of Hybrids I and II. DECPSK I was also consistently inferior to DPSK $I$ in the presence of multipath. In general, the performance achieved with this modem corresponds to that achieved by Hybrid I and Hybrid II.

\subsection{DECPSK II}

The performances achieved by a relatively unsophisticated DECPSK modem are shown in Figure 7 . This system provides performance which is roughly $2 \mathrm{~dB}$ from theoretical in the presence of gaussian noise on $1 y$. The addition of multipath effects causes significant further degradation, as shown in Figure 7 . Note that the performance at $\mathrm{C} / \mathrm{M}=11 \mathrm{~dB}$ in this modem is comparable to the other DECPSK modems when $\mathrm{C} / \mathrm{M}$ is roughly $5 \mathrm{~dB}$.

\subsection{EFFECTS OF A HARD LIMITING SATELLITE TRANSPONDER}

The effects of a hard limiting satellite repeater of a type considered for aeronautical satellites were simulated in the laboratory by adding an IF processor subsystem in cascade with the channel simulator. The IF processor was provided by the General Electric Company. The performance of the Hybrid I modem, including the effect of the hard 1 imiting IF processor, is shown in Figure 8. In this test configuration the overall performance was only $1 \mathrm{~dB}$ $1.2 \mathrm{~dB}$ below theoretical in the absence of multipath. Once again, the performance achieved is comparable to that of the other DECPSK test runs.

Finally, Figure 9 shows the effect of relative Doppler shift on the DECPSK modem in this test configuration. At $\mathrm{C} / \mathrm{N}_{0}=44.8 \mathrm{~dB}$, $D=100 \mathrm{~Hz}$, and $\mathrm{C} / \mathrm{M}=5 \mathrm{~dB}$, very little effect is observed. These results are similar to those achieved with the DPSK modem as shown in Figure 5. Figure 9 shows that at higher $C / N_{0}$ and 1 ower $D$, the effect of relative Doppler shift is more significant. Specifically, with Doppler spread set at $10 \mathrm{~Hz}$ and relative Doppler set at values 


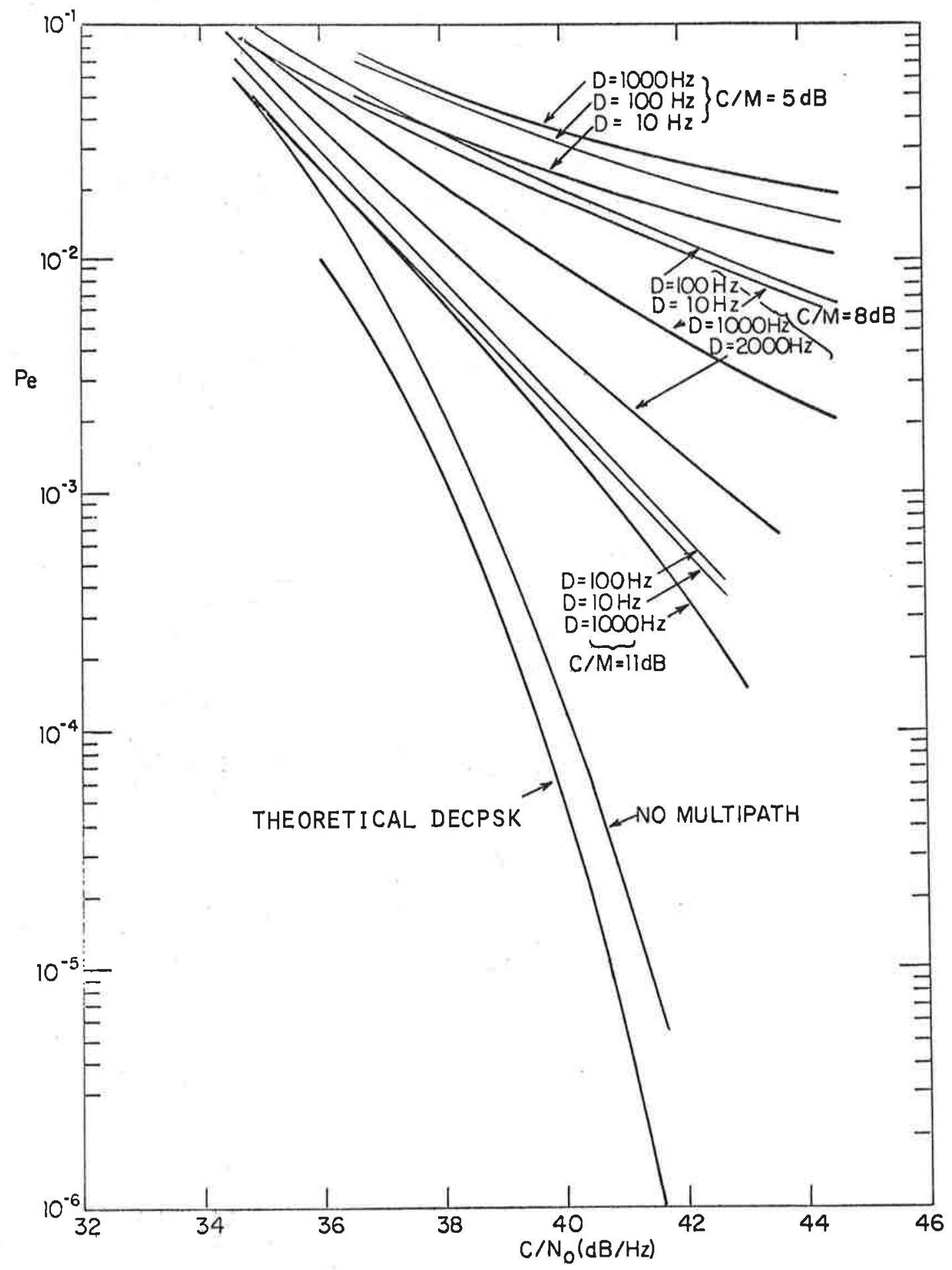

Figure 6. DECPSK I Performance 


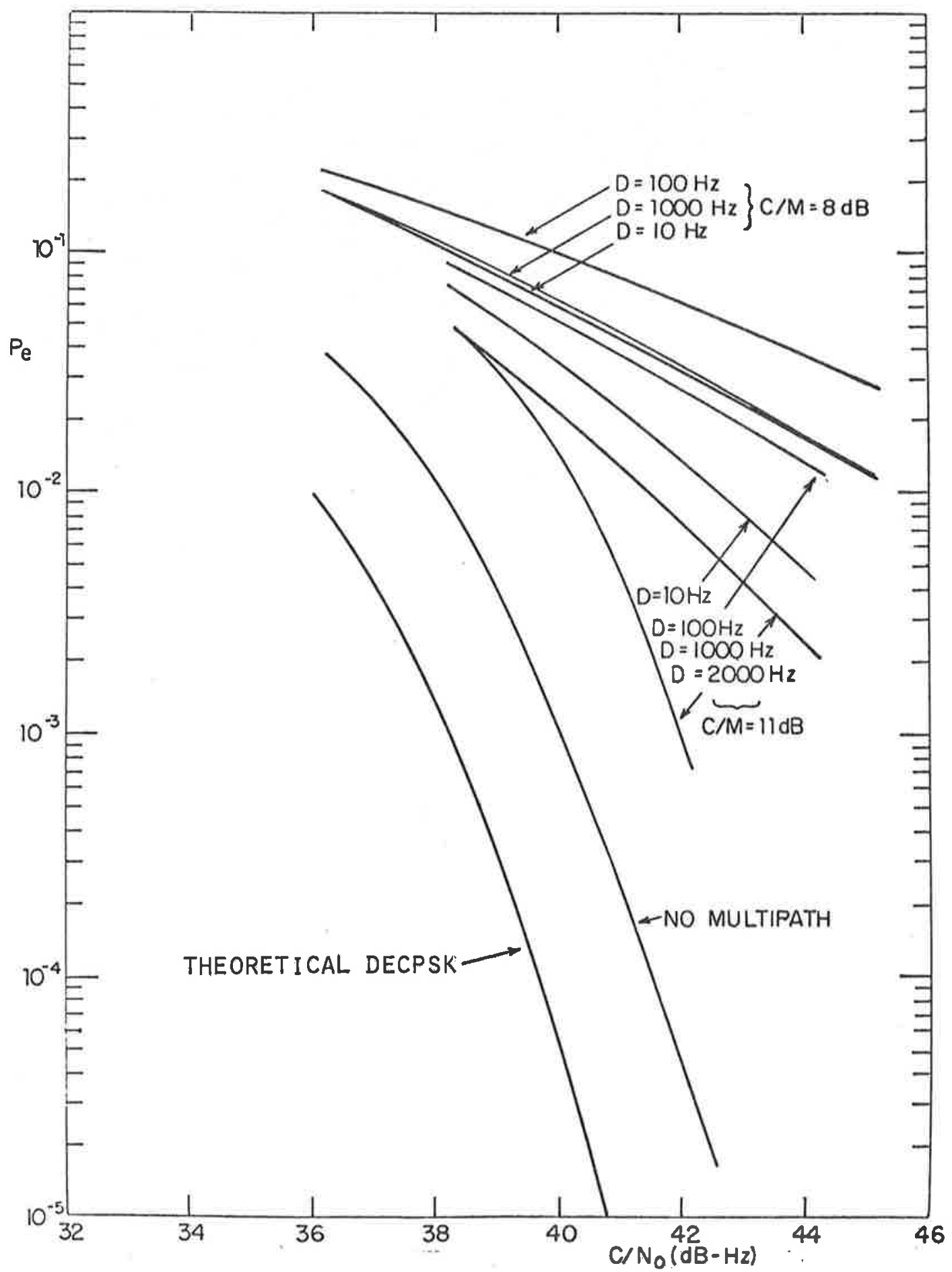

Figure 7. DECPSK II Performance 


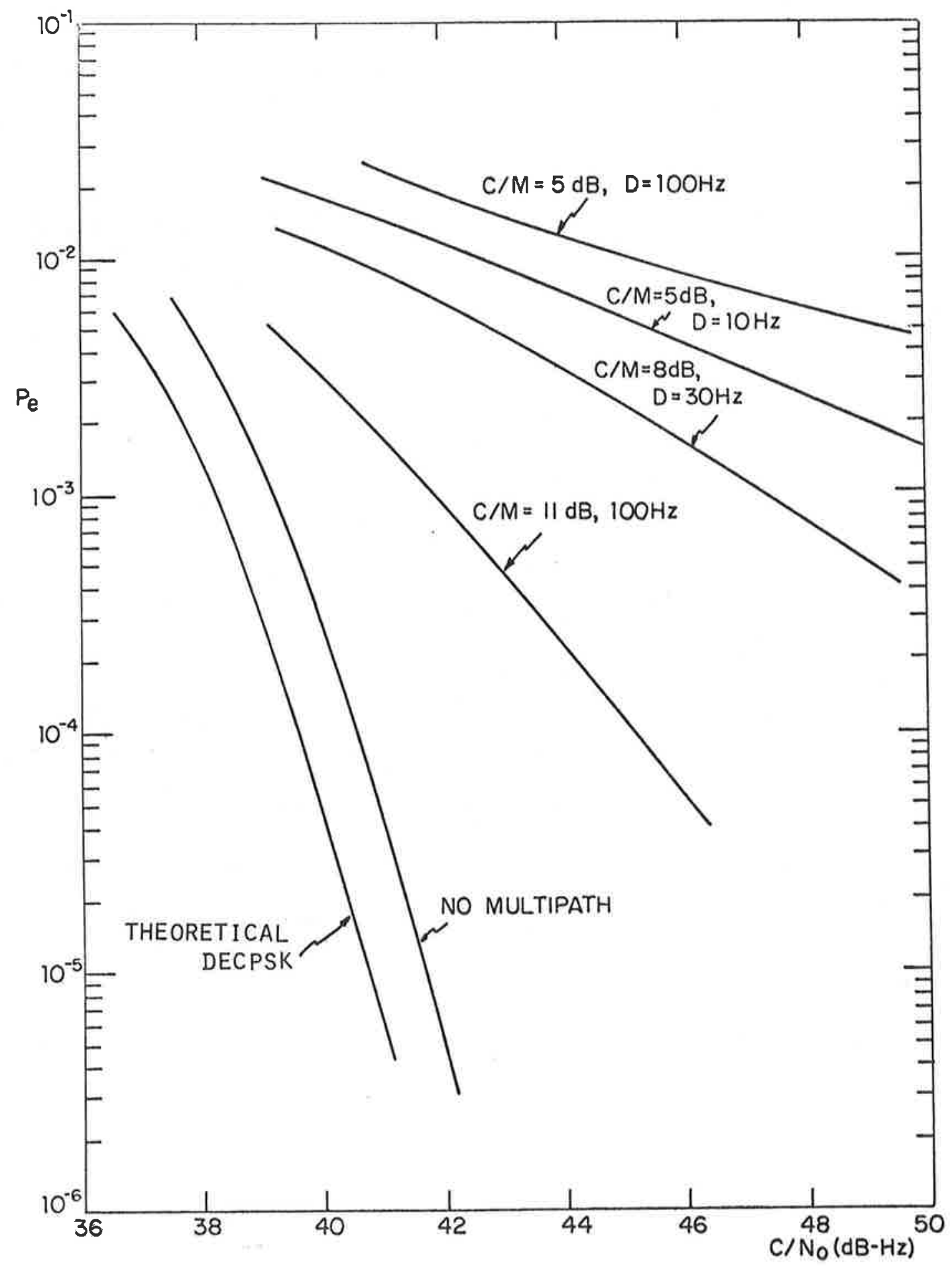

Figure 8. Hybrid I Performance with IF Processor 


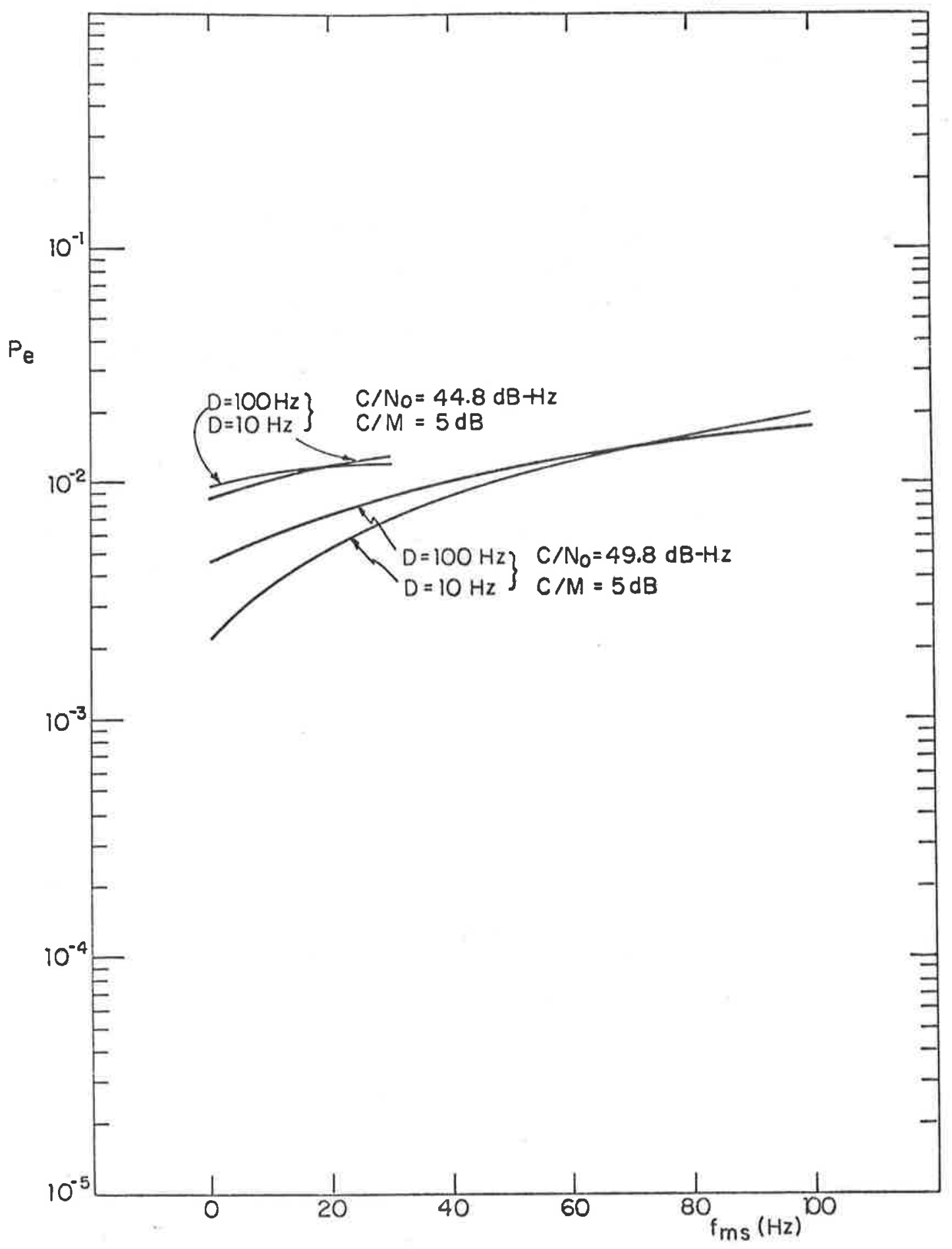

Figure 9. Doppler Offset Effects 
much greater than $10 \mathrm{~Hz}$, the carrier tracking loop is presented with a disturbance which is increasingly offset relative to its center frequency. It appears that this condition is more likely to induce carrier referency cycle-slips and hence bit errors in the DECPSK implementation. However, such conditions are not likely to be encountered in normal commercial aircraft geometries. 


\section{ANALYSIS OF RESULTS}

It should be noted that $\mathrm{C} / \mathrm{N}_{\mathrm{O}}$ measurement uncertainty on the order of $0.5 \mathrm{~dB}$ corresponds to an error rate multiplier of roughly 1.15 at $C / M=5 \mathrm{~dB}, 1.25$ at $\mathrm{C} / \mathrm{M}=8 \mathrm{~dB}$, and roughly 1.4 at $\mathrm{C} / \mathrm{M}=11$ dB. Nonetheless, the consistency and repeatibility of the tabulated data allows us to draw definite conclusions about the performance of the modems in the presence of multipath.

First, consider a comparison of performance of Hybrid I to Hybrid II. Although these modems provide similar performance in the presence of gaussian noise, the addition of multipath components results in noticeable performance differences. In general, Hybrid I provides better performance in the presence of multipath than Hybrid II. For example, with $\mathrm{C} / \mathrm{M}=11 \mathrm{~dB}$, Hybrid II requires $\mathrm{C} / \mathrm{N}_{0}$ to be higher by roughly $1.4 \mathrm{~dB}$ to provide the same performance as Hybrid I averaged over the range from $40 \mathrm{~dB}-\mathrm{Hz}$ to $46 \mathrm{~dB}$ and over $\mathrm{D}=10 \mathrm{~Hz}, 100 \mathrm{~Hz}$, and $1000 \mathrm{~Hz}$. Similarly at $\mathrm{C} / \mathrm{M}=8 \mathrm{~dB}$, Hybrid II requires $\mathrm{C} / \mathrm{N}_{\mathrm{O}}$ to be $1.5 \mathrm{~dB}$ greater for the same average performance. With $\mathrm{C} / \mathrm{M}=5 \mathrm{~dB}$, the performance difference is roughly $0.8 \mathrm{~dB}$ in favor of Hybrid I. Noting the slope of the BER curves at $C / M=$ $5 \mathrm{~dB}$, it is seen that this 1 atter performance is very small when expressed in terms of BER degradation.

This observed performance trend is difficult to explain on theoretical grounds since it involves a complex interaction of the signa1, noise, and multipath components with the modem's detection, carrier loop, and bit synch loop circuitry. It is likely, however, that minor differences in IF filter characteristics, 1oop compensation techniques, and other similar factors are responsible for the performance difference, since both systems have the same general block diagram when operated in the data-only mode.

Next, consider the comparison of the Hybrids with DECPSK I. The performances achieved by DECPSK I are remarkably similar to those of the Hybrids (which are also DECPSK implementations). In genera1, when $C / M=11 \mathrm{~dB}$, the performance of DECPSK $I$ is worse than Hybrid I but better than Hybrid $I I$. When $C / M=8 \mathrm{~dB}$ or $5 \mathrm{~dB}$, 
DECPSK I is slightly worse than Hybrid II. This indicates that DECPSK is marginally more vulnerable to multipath than the Hybrid modems. The increased vulnerability may be explained by the fact that the carrier tracking loop in DECPSK I is wider in bandwidth than those of the Hybrids. The increased bandwidth could also explain the degradation observed in DECPSK I performance when $D$ is increased from $10 \mathrm{~Hz}$ to $100 \mathrm{~Hz}$. That is, the narrower loops will reject a greater percentage of the multipath energy as the Doppler spread is increased, thereby causing an overall improvement in BER. The wider loop would attempt to follow the multipath induced phase fluctuations, but would have significant tracking errors due to noise and dynamic servo lag.

The DPSK I modem performance is compared to that of Hybrid I in Table 3. Table 3 shows the added $\mathrm{C} / \mathrm{N}_{0}$ required by Hybrid $\mathrm{I}$ to achieve the performance of DPSK I, all other factors equal. Since the slopes of the various performance curves are not equal, the improvement of DSPK I over Hybrid I cannot be expressed as a single number. Instead we note that the DPSK I performance is inferior or approximately equal to that of Hybrid $\mathrm{I}$ where $\mathrm{C} / \mathrm{N}_{\mathrm{o}}$ is low and BER is correspondingly high. As $\mathrm{C} / \mathrm{N}$ is increased, the steeper slopes of the DPSK I performance curves result in better performance comparisons for the modem. The DPSK I performance advantage rapidly diverges to significant values at the higher $\mathrm{C} / \mathrm{N}_{\mathrm{o}}$ ratios.

The DECPSK II modem was seen to provide inferior performance under all conditions. In fact, it could not remain in lock in a $5 \mathrm{~dB}$ multipath environment.

Finally, we can compare the performance achieved by the Hybrid I modem with and without a hard limiting IF processor in cascade with the simulator system. Figure 8 shows that the IF processor has a small degrading effect when the multipath is around $11 \mathrm{~dB}$ down. The average degradation is roughly $0.8 \mathrm{~dB}$ in the region from $40 \mathrm{~dB}-\mathrm{Hz}$ to $46 \mathrm{~dB}-\mathrm{Hz}$ with $\mathrm{D}=100 \mathrm{~Hz}$. Similar results are achieved with $\mathrm{C} / \mathrm{M}=8 \mathrm{~dB}$. Extrapolating from the data in Figures 3 and 8 it is found that the average degradation is roughly $1.1 \mathrm{~dB}$ in the region from $40 \mathrm{~dB}-\mathrm{Hz}$ to $46 \mathrm{~dB}-\mathrm{Hz}$ with $\mathrm{D}$ on the order of $30 \mathrm{~Hz}$. Finally, at $\mathrm{C} / \mathrm{M}=5 \mathrm{~dB}$ the average degradation is roughly 


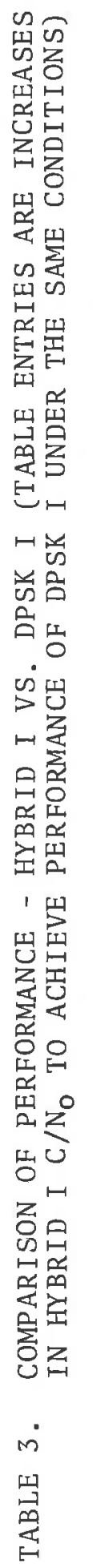

\begin{tabular}{|c|c|c|c|c|c|}
\hline $\begin{array}{l}0 \\
1 \\
\circ \\
-1 \\
x \\
n \\
11 \\
0 \\
0 \\
2 \\
4 \\
0 \\
4 \\
0 \\
z \\
0 \\
0\end{array}$ & 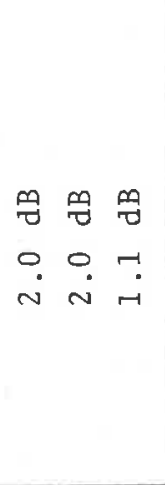 & $\begin{array}{c}m \\
1 \\
0 \\
-1 \\
11 \\
0 \\
0 \\
5 \\
0 \\
\dot{4} \\
z^{0} \\
u \\
u\end{array}$ & 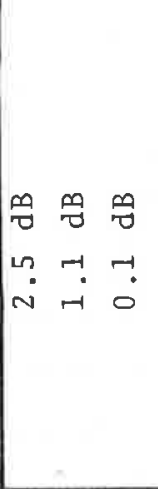 & $\mid \begin{array}{c}1 \\
1 \\
0 \\
-1 \\
11 \\
0 \\
0 \\
0 \\
0 \\
4 \\
4 \\
0 \\
z \\
0 \\
\end{array}$ & 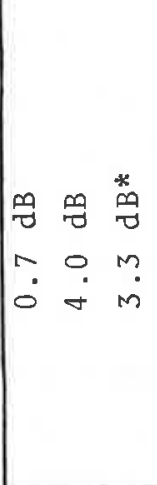 \\
\hline $\begin{array}{c}7 \\
0 \\
0-1 \\
11 \\
0 \\
0 \\
4 \\
0 \\
4 \\
0 \\
z \\
u \\
u\end{array}$ & 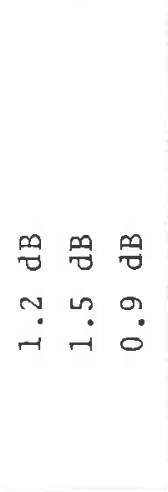 & 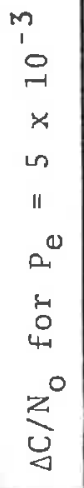 & 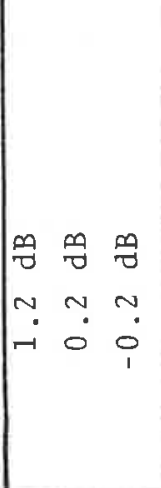 & 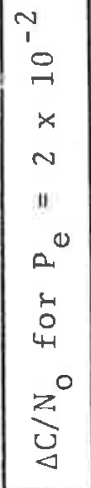 & $\begin{array}{lll}\infty & m & \varphi \\
0 & 0 & \theta \\
\sim & 0 & m \\
0 & -1 & -\end{array}$ \\
\hline $\begin{array}{l}3 \\
1 \\
0 \\
0 \\
11 \\
0 \\
0 \\
0 \\
0 \\
\dot{1} \\
0 \\
z \\
0 \\
0\end{array}$ & 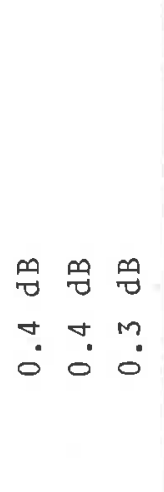 & 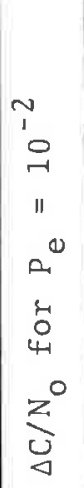 & $\begin{array}{lll}\mathscr{m} & m & 9 \\
0 & 0 & 0 \\
0 & 0 & 0 \\
0 & 0 & 0\end{array}$ & 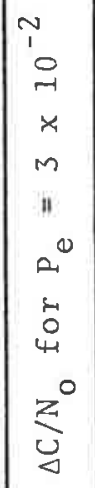 & 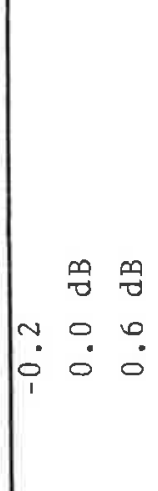 \\
\hline 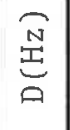 & $\begin{array}{lll} & \circ & 8 \\
\circ & \circ & 8 \\
ㄱ & \circ & \circ \\
-1 & -1\end{array}$ & & $\begin{array}{l}0 \\
0\end{array}$ & & 익 \\
\hline$\sum_{0}^{\Sigma}$ & 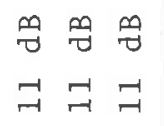 & & 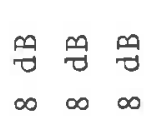 & & 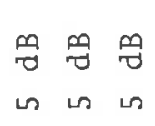 \\
\hline
\end{tabular}


$0.5 \mathrm{~dB}$ over the range from $40 \mathrm{~dB}-\mathrm{Hz}$ to $46 \mathrm{~dB}-\mathrm{Hz}$ and with $\mathrm{D}=10$ $\mathrm{Hz}$ and $100 \mathrm{~Hz}$. It is interesting to note the apparent improvement caused by the IF processor in the vicinity of $\mathrm{C} / \mathrm{M}=5 \mathrm{~dB}, \mathrm{C} / \mathrm{N}_{\mathrm{o}}=$ $46 \mathrm{~dB}-\mathrm{Hz}, \mathrm{D}=100 \mathrm{~Hz}$. This aberation may be the result of experimental error. On the other hand, it may result from suppression of the multipath component relative to the direct path and receiver noise components which is caused by the limiting action of the IF processor. In general, it is concluded that the hard limiting IF processor will have a small degrading effect on modem system performance, on the order of $0.8 \mathrm{~dB}$, which is attributed to the limiter 1 oss. 


\section{CONCLUSIONS}

A variety of data modems were tested under simulated noise and multipath conditions to determine expected bit error rate performance. The range of conditions chosen are those which may be encountered primarily at low elevation angles on over-ocean satelliteto-aircraft links using typical aircraft antennas. The results are presented in parametric form so that they can be applied to estimate the performance of these data modems given specific propagation geometries and specific antenna characteristics.

The simulation experiments described have successfully provided performance evaluation data for a variety of data modems operating in a multipath environment. In general, the results conform to previously obtained experimental data. ${ }^{10,11}$ More important, the experience with the simulation equipments provides us with some insight into the complex interaction of signal, noise, and multipath with the modem detection, carrier tracking, and bit-synchronization circuitry.

Practical results include a performance comparison of DPSK with DECPSK which shows that while DSPK is inferior to DECPSK in the presence of gaussian noise only, it is superior to DECPSK in the presence of multipath at useful error rates. The rapid deterioration of DECPSK performance in the presence of multipath is most likely the result of multipath induced phase errors in the coherent demodulation reference extraction process. Small phase errors in the carrier loops of such systems have significant effects on performance in the low BER region. Furthermore, deep fading of the received signal will cause cycle-slips in the carrier loops which will result in bursts of errors. The performance of DPSK degrades less in the presence of multipath since coherent tracking of the received carrier is not required.

Comparisons among the DECPSK implementations showed that substatial differences in performance can result from differences in the design of carrier and bit-synch loop circuitry. For the 
aircraft-satellite case, such loops should be optimized for expected carrier-to-noise ratios, aircraft dynamics, carrier-tomultipath ratios, and expected Doppler spreads.

Interesting results were obtained with an IF processor in cascade with the aeronautical channel simulator. The IF processor which filters and limits the sum of the direct path signal, multipath signals, and receiver noise appears to cause a slight degradation in performance. The receiver noise predominates over the signal in the limiter, which results in approximately $1 \mathrm{~dB}$ loss in $\mathrm{C} / \mathrm{N}_{0}$. However, the multipath may also be suppressed slightly with respect to the signal, which would result in a slight performance improvement. The net effect appears to be an average degradation of $0.8 \mathrm{~dB}$. The significant factor seen here is that nonlinear processing of the sum RF signal resulted in no additional degradation beyond that normally encountered in a 1 imiting IF. 
REFERENCES

1. J. J. Jones, "Multichannel FSK and DPSK Reception with Three Component Multipath," IEE Trans. Comm. Tech. Vol. COM-16, December 1968 .

2. L. A. Frasco and H. D. Goldfein, "Signal Design for Aeronautical Channels," IEE Trans. Comm. Tech. Vo1. CCM-21, May 1973.

3. H. Salwen, "DPSK Performance Under Time Selective Multipath Fading," IEE Trans. Comm. Soc., March 1975.

4. R. Wachsman, H. Salwen, L. Klein and R. Zaorski, "Study of a Multipath Rejection Technique Applied to Aircraft Navigation by Satellite," NASA Contract No. NA512-567 for E1ectronics Research Center, Cambridge, Mass., 15 March 1969.

5. A Simulator to Produce Narrow Band Multipath Effects on L-Band Aircraft to Satellite Signals, Final Report Prepared for D.0.T. Transportation Systems Center under Contract No. DOT-TSC-372, May 1973 .

6. J. K. De Rosa, "On the Determination of the Delay-Doppler Scattering Function for a Ground-to-Aircraft Link," Symposium Digest, 1970, Canadian Symposium on Communication, November $12,13,1970$.

7. H. Salwen, "Characteristics of Satellite-to-Aircraft Links," Convention Record, International Communication Conference, ICC 71,1971 .

8. P. A. Bello, "Aeronautical Channel Characterization," IEEE Trans on Comm. Vol. COM-21 No. 5, May 1973.

9. A. J. Mallinckrodt, "Propagation Effects." Notes for a UCLA short course, "Satellite Based Navigation, Traffic Control and Communications to Mobile Terminals," September 14-25, 1970.

10. S. Wilson, "Satellite-Aircraft Digital Transmission Experimental Results at L-Band," Int'l Telemetering Conference, Washington, D. C., October 11,1973 . 


\section{REFERENCES (CONTINUED)}

11. ATS-5 Mu1tipath/Ranging Digital Data L-Band Experimenta1 Program, Final Report No. FAA-RD-73-57, Boeing Commercial Airplane Group. Prepared for FAA Systems Research and Development Service under Contract DOT-FA69 WA-2109, April 1973. 
